\title{
Investigating Risk Factors Influencing Safety in National Highways in Sudan
}

\author{
Magdi Mohamed Eltayeb Zumrawi \\ Department of Civil Engineering, University of Khartoum, Khartoum, Sudan
}

Email address:

magdi.zumrawi@yahoo.com

\section{To cite this article:}

Magdi Mohamed Eltayeb Zumrawi. Investigating Risk Factors Influencing Safety in National Highways in Sudan. American Journal of Civil Engineering. Vol. 4, No. 6, 2016, pp. 276-281. doi: 10.11648/j.ajce.20160406.12

Received: August 6, 2016; Accepted: August 16, 2016; Published: September 2, 2016

\begin{abstract}
Road safety is an issue of vital concern to road authorities. Detecting accidents risk factors can contribute to make a road more efficient, safe and comfortable. The research is focused on safety problems related to road surface conditions, traffic facilities, and road users' behavior. Eight major national highways were selected to serve as the case study and assumed to represent highway networks in Sudan. A field survey of the current safety conditions was conducted on the selected highways. For each highway, the previous occurred accidents, road surface problems, and inadequate traffic control facilitieswhich directly related to road safety were visually surveyed. To achieve the research objective, a new rating system called "Risk Factor Index" (RFI) was established and adopted to measure the safety hazards condition on the selected highways. The results showed that all the surveyed highways scored "Medium" level of RFI except one road scored "low" level of RFI. It was found that the major risk factors of the highest RFI are improper road width, absence of median and deficiency in road lighting and marking. Based on the study findings, recommendations of necessary corrective measures were provided to enhance road safety.
\end{abstract}

Keywords: Accidents, National Roads, Risk Factors, Road Safety, Road Users

\section{Introduction}

Traffic safety is an essential component of transportation management. Many efforts have been made by management operators in order to contribute to a consistent reduction of accident risks. In fact, road accidents are a leading cause of death and injury worldwide and it becomes a matter of great personal tragedy, tremendous social and economic costs in terms of valuable lives lost, medical treatment, insurance and damage to public and private property. Globally, the number of people killed in traffic accidents every year is estimated at almost 1.17 million, while the number of injured could be over 10 million [1].

The road safety situation in Sudan is one of the worst in neighboring countries, with 2000 fatalities in 2009. The significant increase observed in recorded accidents between 1990 and 2009 was due to the increase of vehicles, long trailers, incompetent drivers and poor road conditions. The average percent of fatality on national highway crashes for the years 2003 to 2005 is about $19 \%$ from total road accident fatality [2].
Road safety audits and safety impact assessment are two Safety tools that offer promise to help reduce roadway crashes and fatalities. Worldwide, these tools have been used by transportation safety professionals since the 1980s. In Sudan many efforts have being done but no national plan is set to deal with this problem. The highway safety has been gradually improved since the establishment of the National Coordination Road Safety Council in 2010 which is formed from the national stakeholders.

The purpose of this study is to identify the risk factors which can contribute to accidents occurrence on the national highways. This objective is the most important task to enhance the safety conditions in our country highways.

\section{Literature Review}

Traffic Safety is an essential issue in transportation engineering. It involves many factors including driver skills, roadway characteristics, vehicle conditions, and weather. In addition to crash causation, the identification of hazards that may increase severity in the event of a crash is important. 
Among all contributing elements, speed is considered to be one of the most critical. Statistics show that speed is a factor in one-third of all motor vehicle fatalities [3]. During the last decades, many resources have been spent by automotive industry for the improvement of road users' protection (both drivers and pedestrian). The most common attempt to control driving speed is imposing speed limits.

Previous studies showed that many elements contribute to determine an unsafe and a distracted driving behavior related to driver's psycho-physical conditions, his mental workload, the reduction of the attention threshold, and the increase of the perception-reaction time [4].

\subsection{Road Accidents}

An accident is "occurrence in a sequence of events which usually produces unintended injury, death or property damage". Accidents represent a major epidemic of noncommunicable disease in the present century. They are part of the price we pay for technological progress [5]. Road traffic injuries are a major; but neglected global public health problem, requiring concerted efforts for effective and sustainable prevention. Of all the system that people have to deal with on a daily basis road transport, is the most complex and the most dangerous [6].

Recent studies have demonstrated that the accident risk, in terms of repeatability, localization and severity, is related to three main factors: (i) vehicle type, depending on both passive and active provided safety systems; (ii) road, in terms of design consistency and pavement surface performance (friction, texture), especially in wet conditions; (iii) driver, who is the main factor for the occurrence of an accident [7]. A more recent study, based on a dataset of 100 vehicles for a year, showed that distractions and inattention (e.g., fatigue) contribute to approximately $80 \%$ of crashes and that distraction contribute to around $65 \%$ of rear-end crashes [8]. The age of the driver also contributes to the attention failure due to a change in visual motion detection [9]. Vehicles features determine about $10 \%$ of the overall accidents; about $30 \%$ of the accidents are related to road characteristics, such as the pavement $(10 \%)$, geometry $(10 \%)$ and other factors include signal, guardrails, safety barriers, etc. (10\%). Accordingly, the most significant factor in an accident is the human behavior $60 \%$ [10-12].

The total cost of road accident is estimated about $1-3 \%$ of total gross domestic product in most of the countries worldwide [1]. During the last ten years, the number of road accidents in Sudan increased at an annual growth rate of $3 \%$. Similarly, the number of road accident fatalities and the number of persons injured in road accidents in the country increased by $5.8 \%$ and $2.4 \%$, respectively [2].

\subsection{Road Safety Mechanism}

The mechanism of addressing roadway safety is the implementation of two safety tools, road safety audits and road safety impact assessment. Road safety audit is a formal procedure for independent assessment of the accident potential and likely safety performance of a specific design for a road project, whether new construction or an alteration to an existing road [13].

Road Safety Audit is an important means for paying explicit attention to road safety during the design of road project. This should help everyone involved in making decisions regarding changes to road infrastructure to assess the safety implications of the many choices that arise during the design process, and thus increase the road safety awareness of infrastructure planners, designers and authorities [14].

Road safety impact assessment is a formal procedure for independent assessment of the likely effects of proposed road project, or indeed other projects that have substantial effects on road traffic, upon accident occurrence throughout the road network upon which traffic conditions may be affected by the projects [15].

The two procedures of safety tools enable the skills of road safety engineering and accident analysis to be used for the prevention of accidents on new or modified roads. They thus complement the use of these same skills to reduce the occurrence of accidents on existing roads by means of local safety projects, in many cases in the form of low-cost measures [15]. The benefits of safety audits and safety impact assessment are in minimizing the risk of accidents occurring in the future as a result of planning decisions on new transport infrastructure schemes; reducing the risk of accidents occurring in the future as a result of unintended effects of the design of road schemes; reducing the long-term costs associated with a planning decision or a road scheme; and enhancing the awareness of road safety needs among policy-makers and scheme designers [14].

\subsection{Accident Risk Factors}

A risk factor is defined as any factor that increases the probability of sustaining an accident or worsens the severity of injuries [16]. The road users must be informed about the risk associated to the road segment they are using in order to prevent or reduce future accidents, especially road where previous fatalities occurred [17]. Several previous studies have identified a number of risk factors influencing the possibility of being involved in a road traffic accident $[7,16$, 17]. The most important factors related to road safety are summarized in Table 1.

Table 1. Main factors affecting road safety (source [16]).

\begin{tabular}{ll}
\hline Factors & Descriptions \\
\hline Road user behavior & $\begin{array}{l}\text { Speed; fatigue; overtaking maneuvers; alcohol; } \\
\text { travelling in darkness; age of drivers; use of seat } \\
\text { belts. } \\
\text { Road surface; inadequate visibility; road alignment; } \\
\text { defects in road design; road junctions; super- } \\
\text { elevation; defects in road maintenance; private } \\
\text { accesses; consistency. }\end{array}$ \\
Road conditions & $\begin{array}{l}\text { Vehicle defects; vehicle size; technical conditions. } \\
\text { Perfect rate of traffic sign; serviceability rate of }\end{array}$ \\
Traffic facility & $\begin{array}{l}\text { traffic marking; traffic accident emergency rescue. } \\
\text { Gross national product; unemployment; urban }\end{array}$ \\
Socio-economic & population; illiteracy. \\
\hline
\end{tabular}


The accidents risk factors are measurable parameters that can be used for assessing and monitoring the risk level on a road. The identification of the factors, which can contribute to an accident occurrence are described below.

\subsubsection{Historical Accidents Data}

The safety level of a road can be evaluated by means of the number and the severity of occurred accidents. Historical accident data are an important indicator of roads safety performance for identification of high-accident locations where the priority of maintenance intervention is defined [18]. However, if no accident occurred in a road section in the past years it seems to be necessary to investigate on other hazardous factors that can determine the risk level of a road segment [19].

\subsubsection{Road Surface Problems}

The road surface problems related to its texture, irregularities and distresses are greatly influence accident rate [20]. Surface friction is an essential component of traffic safety because it provides the grip that a tire needs to maintain vehicle control and for stopping in emergency conditions especially in wet weather. The presence of distresses such as potholes and rutting on the road surface causes discomfort and pose safety risks to drivers [21-23]. Previous studies showed that increasing road surface unevenness and rut depth determines an increase in accident by $2.3 \%$ after 10 years and by $4.8 \%$ after 20 years $[7,24]$.

\subsubsection{Operating Speed Variance}

The relation between speed and safety is complex. Speed seems to contribute to accident occurrence and deviation from average traffic speeds appears to be an accident risk factor. Speed variance appears to play the most important role in the relationship between speed and accident involvement rate. From this point of view, road safety campaigns and enforcement strategies should focus on reducing speed variance and conflicts resulting from large speed differences. Stuster [25] found that when speeds deviated greatly from the average speed, either faster or slower, the risk to be involved in an accident was high, whereas speeds close to the average speed present low accident risk. The results obtained by West and Dunn [26] showed that $4 \%$ of drivers operate their vehicles at excessive speeds that create a hazard to themselves and others that share the road. This risky group of drivers has an accident involvement rate which is more six times that of the remaining $96 \%$.

\subsubsection{Poor Road Lighting and Marking}

The accident risk is primarily affected by poor or missing road lighting which has adverse effects on road visibility and sight distances. Deficiencies in road marking are referred to edge lines missing or inadequate, centre-line missing or inadequate, and no-overtaking line missing, especially where passing sight distance is not provided. The accident risk isprimarily affected by no overtaking line missing in this case the rate of accidents can increase by $50 \%$ [22]. Moreover, an increase in injury accidents risk was recorded for edge lines missing $8 \%$ and for centerline missing $13 \%$ [22].

\subsubsection{Ineffective Traffic Control Facilities}

The traffic control devices and equipment such as traffic signals and road signs are used to control and facilitate the traffic flow in road at intersections and carriageways.A traffic signal normally is placed along the roadway to control the driver, transmitting an unambiguous, quick and clear message to road users [27]. Road signs that have the greatest effect on traffic safety are warning signs, since they call attention to hazardous situations [28]. In their research work, Wilkie and Fergus [22] found that the relative risk factor for missing or ineffective curve warning signs on severe curves was fixed to $10 \%$.

\subsubsection{Inadequate Safety Barriers}

A roadside barrier is one of the most common best practices for road traffic safety improvement. The roadside configurations that are commonly associated with fixedobject crashes placed in close proximity to the lane edge, the presence of objects placed near lane merge points, etc. Furthermore, when an accident occurs, crash barriers along the roadway allow the kinetic energy of the vehicle to be absorbed as they are deformed over a distance. In this way, human errors do not necessarily end in death or serious injury [29]. Risk increase for inadequate safety barriers was estimated to be equal to $60 \%$. This rate was calculated by taking into account analytical relationships between a barrier's containment capacity and impact conditions that allow evaluating the number of vehicles successfully redirected in relation to the safety barriers containment level [30].

\section{Case Study}

As the research objective is to identify the main factors that contribute to accidence occurrence and influencing the safety conditionsin the highway. To achieve the objective, eight national highways were selected to serve as the case of research and are assumed to be representative of highways in Sudan. The investigation program consisted of two tasks: the first task concerns with reviewing of recorders and documents, whereas the second task coveredthe visual inspection of the current safety situation in the selected highways.

\subsection{Project Description}

Sudan has a highway network of about 30,000 kilometers length. This network spreads on a wide land area of the country. The paved highways represent $20 \%$ of the network and most of them are located in the northernandcentral parts of the country. Almost $50 \%$ of the paved highways were constructed during the period 1989 - 2005 [31]. For the purpose of this study, eight major national highways were selected for investigation. These highways were surveyed for safety problems linked to road condition and traffic facilities are listed in Table 2. 


\subsection{Data Collection}

The investigation started with reviewing of available documents and reports to collect relevant information about design, construction and maintenance stages of the project. The documents collect include previous accident records; design sheets and reports; traffic studies and other relevant documents. These documents and records were reviewed to give initial impressions and used to plan for the site inspection. Appropriate check list of a number of risk factors was prepared to refer during the site survey. The accidents data collected in the year 2015 are given below in Table 2.

Table 2. The basic information and the previous accidents data of the project highways [1].

\begin{tabular}{|c|c|c|c|c|}
\hline Highway Name & ID & Length (Km) & Accidents & Fatalities \\
\hline $\begin{array}{l}\text { Khartoum - Wad } \\
\text { Medani }\end{array}$ & $\mathrm{H} 1$ & 160 & 111 & 163 \\
\hline Khartoum - Atbara & $\mathrm{H} 2$ & 310 & 64 & 96 \\
\hline Khartoum -Elobiedb & H3 & 550 & 96 & 153 \\
\hline $\begin{array}{l}\text { Omdurman - } \\
\text { Dongula }\end{array}$ & $\mathrm{H} 4$ & 500 & 38 & 56 \\
\hline Atbara - Port Sudan & H5 & 485 & 38 & 63 \\
\hline Kassala - Port Sudan & H6 & 557 & 45 & 70 \\
\hline $\begin{array}{l}\text { Wad Medani - } \\
\text { Kassala }\end{array}$ & H7 & 447 & 71 & 117 \\
\hline $\begin{array}{l}\text { Wad Madani - } \\
\text { Damazine }\end{array}$ & $\mathrm{H} 8$ & 341 & 33 & 68 \\
\hline Total & & 3350 & 496 & 786 \\
\hline
\end{tabular}

\subsection{Field Survey}

After reviewing the available records and documents, the author with the technical team visited the project sites. The prepared checklists of risk factors were used during the site visits. Many visits at daytime and nighttime were conducted to the sites. The inspection was carried out by driving a car at the normal speed along a road during normal traffic flow.

The field survey program included visual inspection of the existing conditions of road surface, traffic control devices and signs, road lighting and marking and roadside safety elements. The GPS navigator was used to locate the position of the problems. Ride quality was used to determine severity level of distresses such as cracking, potholes, rutting, depression, patching, lane/shoulder drop off, etc.

\subsection{Development of Risk Factor Index (RFI)}

An attempt has been made to establish a rating system for the road safety hazards related to the road surface conditions, previous accidents, traffic control facilities and other safety features. The rating system consists of identification number for each surveyed item and rating score according to its availability and conditions.

The Risk Factor Index (RFI) is defined as a numerical indicator which rates the safety hazards condition of the existing road. The developed factor is adopted to measure the present condition of the risk factors observed on the surveyed road. The RFI provides feedback on road safety performance for validation or improvement of current road design and maintenance procedures.

A numerical rating of the RFI ranges from (0) to (10) with
(0) being the lowest possible condition and (10) being the highest and worst possible condition. A verbal description of road safety hazard condition as a function of the RFI value that varies from "Very low" to "Extreme" is shown in Figure 1.

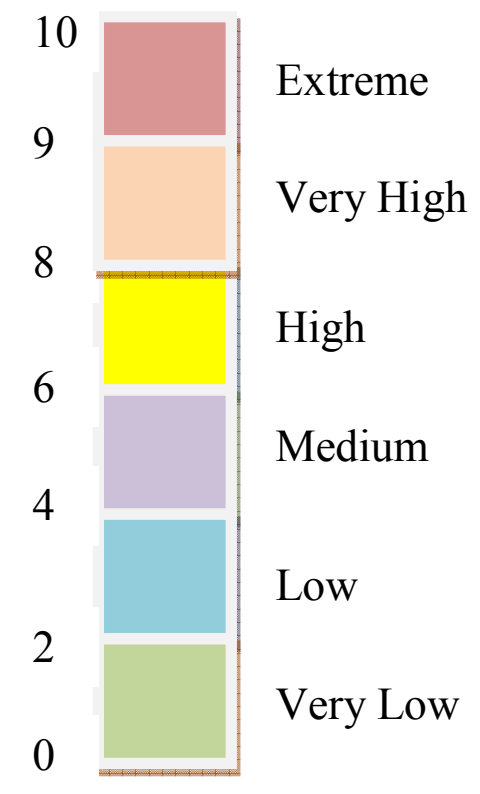

Figure 1. The proposed Risk Factor Index (RFI).

The total length of the highways selected for the study is $3350 \mathrm{~km}$; the field survey covered more than $70 \%$ of the total length in order to assure the reliability of the data obtained. For the purpose of easy and accurate assessment of road safety condition, the developed Risk Factor Index (RFI) was considered in the analysis procedure to link each road with its information files containing surveyed risk factors such as adverse geometric features conditions, poor road surface conditions, accident history, problems related to traffic control devices, road lighting and marking and roadside safety elements, and any other relevant risk factor. For each road, there are estimated values of RFI for the described risk factors that were considered in the field survey.

\section{Results and Discussion}

The results of the field survey conducted on national highways are presented in Table 3. It shows the estimated values of the risk factor index (RFI) for the surveyed highways. It can be observed that all the surveyed highways scored "Medium" level of RFI except one road scored "low" level of RFI. This result indicated that there are safety hazards in most of the national highways. Improper road width and absence of median were found as the primary risk factors (i.e. the highest value RFI $=7.3$ ). These problems may cause traffic congestion and unregulated traffic flow. It is noticed that the risk factor deficiency in road lighting and marking has scored high value (i.e. RFI $=7.1$ ) which means dangerous during night to the drivers. The lowest risk factor $(\mathrm{RFI}=2.6)$ recorded for improper super-elevation at horizontal curves. 
Table 3. Summary of safety assessment results for the project highways.

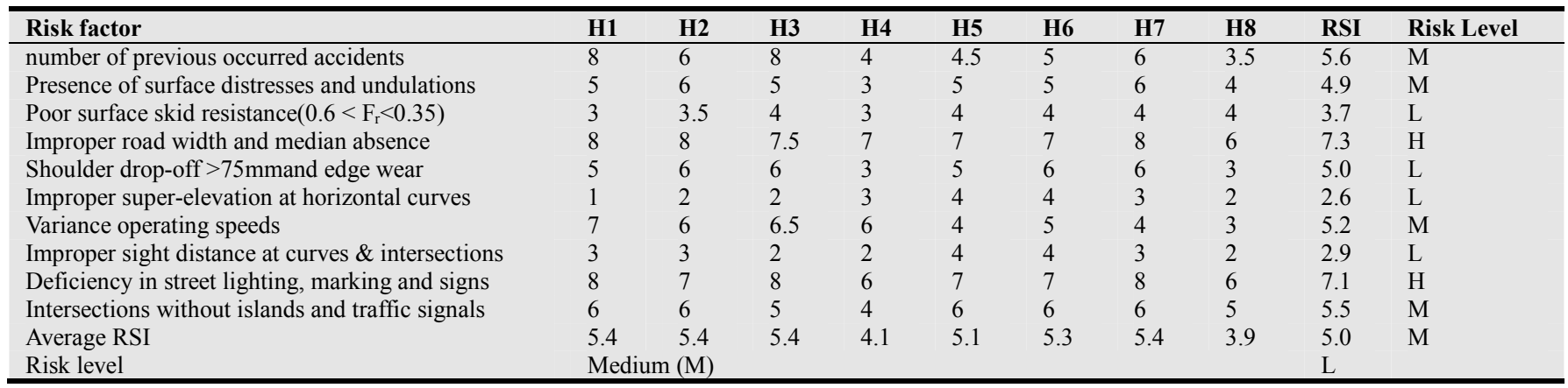

Figs 2 and 3 show the accidents occurred on the surveyed highways during the period from 2010 to 2015 . From figures, it is observed that the highest accident rate and fatalities occurred on Khartoum - Wad Medani highway compared to other highways. Accordingly, the most significant factor in an accident is the narrow carriageway and absence of median in particularly Khartoum - Wad Medani highway. Moreover, all surveyed highways showed a reduction in accident rate more than $50 \%$ in 2015 . The main reasons for this reduction in accidents may be due to the rehabilitation of some national highways in the last five years. The establishment of the National Coordination Road Safety Council in 2010 which is formed from the national stakeholders may also has an effect on accidents reduction.

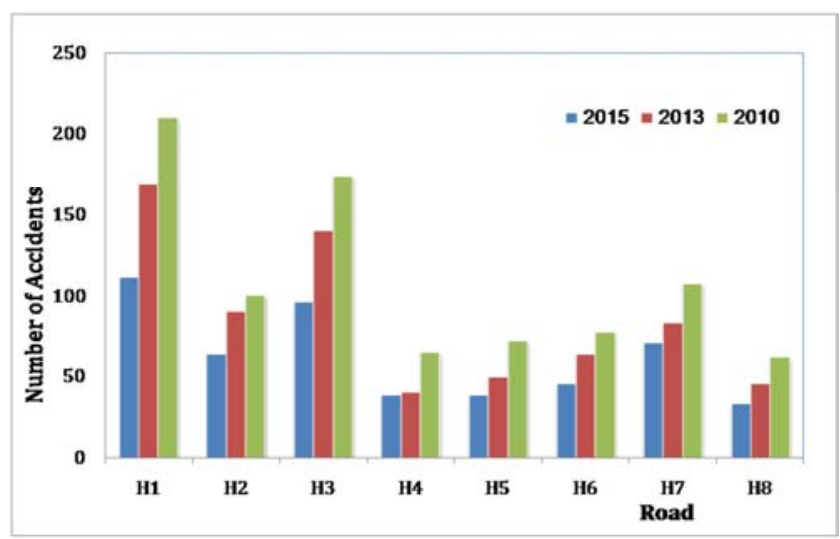

Figure 2. Accidents occurred on the project roads during the period $2010-$ 2015.

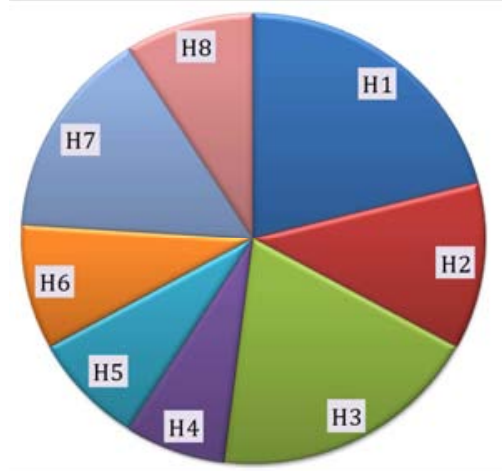

Figure 3. The previous accidents occurred in the surveyed highways in 2015.

\section{Conclusions}

This study has been undertaken to investigate the accidents risk factors in national highways. The results and important conclusions drawn from this study are summarized as follows:

- Road accidents are a major problem, requiring concerted efforts for effective and sustainable prevention.Therefore, understanding the accidents risk factors is quite important.

- Many factors affecting accidents occurrence like poor surface condition, historical accidents data, ineffective traffic facilities, and other safety hazards factors were reviewed in literature and selected for estimation of the Risk Factor Index (RFI) in existing road.

- It is expected that this study will be beneficial for investigating the effectiveness of various accidents risk factors in order to enhance the awareness of road safety needs among policy-makers and scheme designers.

- Road authorities should give higher priorities to road safety than corrective maintenance. In essence, by applying safety improvement, the road authorities can effectively decrease the need for future corrective maintenance while spending less overall.

- Good way to improve safety in existing highways in Sudan network is to consider widening of carriageways, provide median to separate opposing traffic flow, and maintain road lighting, markings and signs.

\section{Acknowledgements}

Author wish to thank the technical team of the department of civil engineering of University of Khartoum for the support provided to the project.

\section{References}

[1] World Bank. Road Safety and Key Issues, available on www.worldbank.org/transport/roads/safety.htm, 2013.

[2] Ministry of Interior Affairs (MIA). Road Accident Statistics, Traffic Police, Ministry of Interior Affairs, Government of Sudan, Khartoum, May 2016. 
[3] Wisconsin Transportation Information Centre (WTIC). Asphalt PASER Manual, Transportation Information Centre, University of Wisconsin-Madison, USA, 2002.

[4] Y. Page. A statistical model to compare road mortality in OECD countries. Accident Analysis \& Prevention,33, 371$385,2001$.

[5] K. Park. Park's Textbook of Preventive and Social Medicine, (20 ${ }^{\text {th }}$ ed.), Banarsi Das Bhanot, Jabalpur, 353, 2009.

[6] M. Peden, R. Scurfield, D. Sleet,D. Mohan, A.A.Hyder,E. Jarawan. World Report on Road Traffic Injury Prevention.World Health Organization, Geneva, 2004.

[7] R. Elvik, T. Vaa, A. Erke, M. Sorensen. The handbook of road safety measures ( $2^{\text {nd }}$ ed.). Emerald Group Publishing Limited, ISBN: 978-1-84855-250-0, 2009.

[8] J. D. Lee. Driving Attention: Cognitive Engineering in Designing Attractions and Distractions. The bridge, Linking Engineering and Society, 38-4, 32-38, 2008.

[9] S. Henderson. Near peripheral motion detection threshold predicts detection failure accident risk in younger and older drivers. Proceedings of the $4^{\text {th }}$ International Driving Symposium on Human Factors in Driver Assessment, Training and Vehicle Design, Stevenson, Washington, July 9$12,2007$.

[10] PIARC, World Road Association. Interazione strada/veicolo Monitoraggio delle caratteristiche edelle azioni del traffico veicolare peril progettoe la manutenzione delle pavimentazioni stradali. XXV National Conference, Naples, Italy, October 4-7, 2006.

[11] D. Mohan, G. Tiwari, M. Khayesi, F. M. Nafukho. Road traffic injury prevention training manual- Unit 2: Risk factors for road traffic injuries. World Health Organization. Indian Institute of Technology Delhi ISBN 924154675 1, 2006

[12] N. Muhlrad, S. Lassarre. Systems approach to injury control. In: G. Tiwari, D. Mohan, N. Muhlrad (Eds.) The way forward: transportation planning and road safety (pp. 52-73) New Delhi, Macmillan India Ltd, 2005.

[13] ETSC. Road Safety Audit and Safety Impact Assessment, B1040 Brussels: European Transport Safety Council, 1997.

[14] AUSTROADS. Road Safety Audit. Sydney: AUSTROADS National Office, 1994.

[15] ETSC. Low-cost road and traffic engineering measures for casualty reduction, Brussels: European Transport Safety Council, 1996.

[16] European Transport Safety Council, ETSC. Transport safety performance indicators. Brussels, ISBN: 90-76024-11-1, 2001.

[17] J. M. Perandones, G. Ramos. Road Safety Index. Ranking for European Road Safety, specific targeted research or innovation project, TREN-04-FP6TR-S07.36996/001678Final Report D4.2, 2008.
[18] H. Hautzinger, C. Pastor, M. Pfeiffer, J. Schmidt. Analysis Methods for Accident and Injury Risk Studies. Project No. 027763 TRACE, 2007.

[19] D. W. Harwood, F. M. Council, E. Hauer, W. E. Hughes, A. Vogt. Prediction of the Expected Safety Performance of Rural Two-Lane Highways. FHWA-RD-99-207, Technical Report, 2000.

[20] R. Vaiana, G. F. Capiluppi, V. Gallelli, T. Iuele, V. Minani. Pavement surface performance evolution: an experimental application. Procedia: Social \& Behavioral Sciences, 53, 1150-1161, 2012. doi: 10.1016/j.sbspro.2012.09.964.

[21] W. J. Steyn, "Evaluation of effects of road maintenance actions on applied tyre loads," $10^{\text {th }}$ Conference on asphalt pavements for Southern Africa, 11-14 September, 2011.

[22] S. Wilkie, T.Fergus. Safety audit of existing roads: developing a less subjective assessment. Transfund report OG/0306/24S, 2003.

[23] J. Shen, A. Rodriguez, A. Gan, "Crash Reduction Factors: a state-of-the-practice survey of State," Departments of Transportation. Proceedings of the $83^{\text {rd }}$ Annual Meeting of the Transportation Research Board, January 10-14, 2004.

[24] P. L. Y. Tiong, M. Mustaffar, M. R. Hainin,"Road Surface Assessment of Pothole Severity by Close Range Digital Photogrammetry Method,"- World Applied Sciences Journal 19 (6) $867-873,2012$.

[25] J. Stuster, Z, Coffman, D. Warren. Synthesis of safety research related to speed.Federal Highway Administration Report FHWA-RD-98-154, U.S. Department of Transportation, Washington DC, July 1998.

[26] L. B. West and J. W. Dunn. Accidents, Speed Deviation and Speed Limits. Traffic Engineering 41(10), pp.52-55, 1971.

[27] G. Ramos, J. M. Perandones, M. Alonso, J. Plaza, H. Vega. RANKERS Final Report. Ranking for European road safety, specific targeted research or innovation project, TREN-04FP6TR-S07.36996/001678- 2008 Final Report D0.2.

[28] A. Montella, "Safety Reviews of Existing Roads Quantitative Safety Assessment Methodology," Journal of the Transportation Research Board, 1922, 62-72, 2005

[29] K. Karen, M. L. Dixon, H. Zhu, M. P. Hunter, B. Mattox. Safe and Aesthetic Design of Urban Roadside Treatments. National Cooperative Highway Research Program, NCHRP REPORT 612, 2008.

[30] A. Montella, "Selection of roadside safety barrier containment level according to European union standards," In Transportation Research Record: Journal of the Transportation Research Board, No. 1743,TRB, National Research Council, Washington, D. C., 104-110, 2001.

[31] National Highway Authority. Road sector Management Program Report. Sponsored by SIDA, Swedish Agency, 2005. 